\title{
Correlation between in vitro fertilization and artificial insemination in Holstein bulls
}

\author{
Wei Sun ${ }^{1,2,3, a}$, Yunxia $\mathrm{Li}^{1,2,3, a}$, Jie $\mathrm{Su}^{3,4}$, Xiangnan Bao ${ }^{3}$, Rui Ding ${ }^{3}$, Gaoping Zhao ${ }^{3}$, Guifang Cao ${ }^{3,4}$,

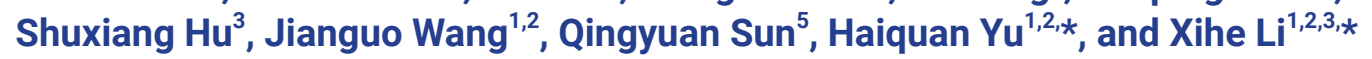

\author{
* Corresponding Authors: \\ Haiquan Yu \\ Tel: +86-44(0)471-3679879, \\ Fax: +86-44(0)471-3679879, \\ E-mail: haiquan_yu@yahoo.com \\ Xihe Li \\ Tel: +86-44(0)471-2383200 \\ Fax: +86-44(0)471-2383200, \\ E-mail: lixh@life.imu.edu.cn
}

'College of Life Science, Inner Mongolia University, Hohhot 010020, China

2 The State Key Laboratory of Reproductive

Regulation and Breeding of Grassland

Livestock, Inner Mongolia University, Hohhot 010020, China

${ }^{3}$ Inner Mongolia Saikexing Institute of Breeding and Reproductive Biotechnology in Domestic Animal, Hohhot 011517, China

${ }^{4}$ College of Veterinary Medicine, Inner

Mongolia Agricultural University, Hohhot 010018, China

${ }^{5}$ Institute of Zoology Chinese Academy of Science, Beijing 100101, China

a These authors contributed equally to this work.

\section{ORCID}

Wei Sun

https://orcid.org/0000-0001-9980-011X Yunxia Li

https://orcid.org/0000-0003-1714-9998

$$
\text { Jie Su }
$$

https://orcid.org/0000-0002-8772-8613 Xiangnan Bao

https://orcid.org/0000-0001-8639-5717 Rui Ding

https://orcid.org/0000-0002-8401-4148 Gaoping Zhao

https://orcid.org/0000-0003-3369-2536

Guifang Cao

https://orcid.org/0000-0002-6177-884X Shuxiang $\mathrm{Hu}$

https://orcid.org/0000-0002-3216-6764 Jianguo Wang

https://orcid.org/0000-0002-5288-7227

Qingyuan Sun

https://orcid.org/0000-0002-0148-2414 Haiquan Yu

https://orcid.org/0000-0002-6342-9125

Xihe Li

https://orcid.org/0000-0003-2371-4332

Submitted Sept 21, 2020; Revised Dec 31, 2020; Accepted Feb 16, 2021
Objective: Owing to the lack of a breeding index for efficient and quick fertility evaluations of Holstein bulls when using traditional or genome-wide detection methods, this study aimed to determine whether in vitro fertilization (IVF) could be used as an indicator of conception rate of artificial insemination (AI).

Methods: Conventional and sexed frozen semen from nine bulls were used for IVF and AI. Results: The IVF and AI conception rates of each bull were confirmed to be positively correlated between the conventional frozen and sexed frozen semen. The correlation coefficient $\mathrm{R}$ values of nine bulls between IVF and AI methods were 0.73 and 0.97 for the conventional frozen and sexed frozen semen, respectively. The average conception rate of three bulls undergoing AI was $69.5 \%$ and $64.2 \%, 61.8 \%$ and $58.8 \%$, and $48.2 \%$ and $46.2 \%$ in first-, second-, and third-born cows when conventional frozen and sexed frozen semen were used, respectively, which showed a positive correlation with the fertilization rate in the same parity. We propose an evaluation standard to assess the fertilization ability of bulls based on their IVF test results, which is categorized into three grades: grade one, normal fertility bull with an AI conception rate of $40 \% \pm 5 \%$ and IVF rate of $45 \%$ to $60 \%$; grade two, higher fertility bull with an AI conception rate of $50 \% \pm 5 \%$ and IVF rate of $61 \%$ to $80 \%$; and grade three, highest fertility bull with an AI conception rate of $60 \% \pm 5 \%$ and IVF rate of $>80 \%$.

Conclusion: These findings reveal that IVF results can be used as a breeding index for bulls to evaluate their AI conception ability, which may shorten the time required to select bulls for breeding.

Keywords: Artificial Insemination (AI); Correlation Analysis; Holstein Bull; In vitro Fertilization (IVF)

\section{INTRODUCTION}

Several factors, including bull semen quality, feeding management, health status, and insemination technology, affect the artificial insemination (AI) conception rate in Holstein cows [1-5]. In contrast to AI, in vitro fertilization (IVF) can be performed under consistent laboratory conditions to complete the fertilization process and early embryo development [6-8]. The conventional method for evaluating the fertilization ability of bulls is the AI test, but it is time-consuming, requires approximately 4 to 5 years, and is expensive; therefore, it is necessary to develop a simple and accurate method for evaluating the AI fertilization ability of bulls [9].

$\mathrm{AI}$ and IVF are widely used treatments for assisted reproduction. AI is the main breeding technology for large-scale cattle breeding, which has been promoted by sexed semen technology in recent years $[10,11]$. Improving the fertilization ability of bulls is one of the 
key measures for increasing the conception rate of AI. IVF is widely used in the production and introduction of livestock embryos [12] and treatment of human infertility. In addition, IVF is a commonly used technique for testing fertilization ability of male animals [13]. The combination of these two technologies will benefit the breeding industry. A previous study [14] performed IVF to investigate validity of IVF in evaluating AI bull fertility. However, to date, there has been no detailed investigation on the relationship between $\mathrm{AI}$ and IVF in sexed frozen semen, which could provide a new index for evaluating bull fertility. In this study, after using either conventional frozen semen or sexed frozen semen, the correlations between IVF and AI conception rates in nine bulls with different breeding abilities were analyzed. The results of this study may provide a new evaluation index for Holstein bull breeding ability and guarantee the efficiency of the industrial application of AI.

\section{MATERIALS AND METHODS}

The Institutional Animal Care and Use Committee of Inner
Mongolia University approved the experimental protocol employed in this study (SYXK2014-0002).

\section{Reagents}

All reagents were purchased from Sigma-Aldrich Co (St. Louis, MO, USA), unless indicated otherwise.

\section{Production of conventional frozen and sexed frozen semen}

Nine Holstein bulls aged 3 to 5 years were randomly selected from the bull station of Inner Mongolia Saikexing Reproductive Biotechnology (Hohhot, China) Co., Ltd. The registration numbers of the bulls are provided in Figure 1. Conventional frozen and X-sexed frozen semen were prepared using the straw freezing procedure. Populations of spermatozoa for conventional and $\mathrm{X}$-sexed frozen semen were 20 million and 2 million, respectively, in each $0.25 \mathrm{~mL}$ straw [6].

\section{In vitro fertilization}

Ovaries were obtained from cows at a local slaughterhouse and were transported to the laboratory at $35^{\circ} \mathrm{C}$ in $0.9 \% \mathrm{NaCl}$
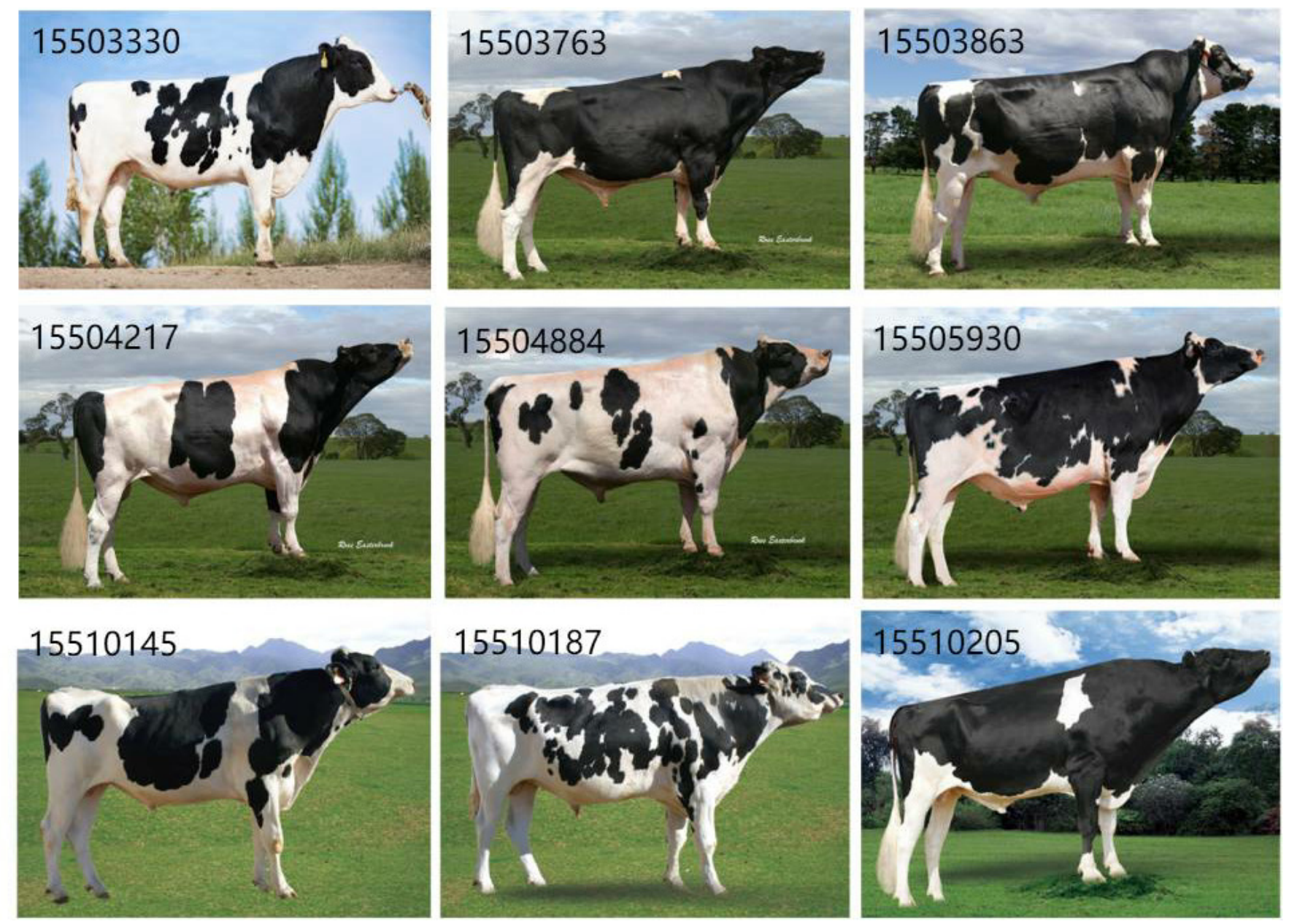

Figure 1. Nine bulls used for this experiment. The number in the upper left of each bull is bull number registered by Holstein Association of China. 
containing $70 \mathrm{mg} / \mathrm{mL}$ kanamycin. Cumulus-oocyte complexes (COCs) were aspirated from medium-sized follicles (approximately $5 \mathrm{~mm}$ in diameter) with a $10-\mathrm{mL}$ disposable syringe. Only COCs surrounded by a compact cumulus mass with an evenly granulated cytoplasm were harvested and then washed thrice in a maturation medium. A total of 60 to 80 COCs were transferred into each well of a Nunc 4-well dish containing $500 \mu \mathrm{L}$ pre-equilibrated maturation medium (TCM199) [15-17] at $38.5^{\circ} \mathrm{C}$ in $5 \% \mathrm{CO}_{2}$ and $100 \%$ humidity. Bull spermatozoa were thawed in a water bath set at $38^{\circ} \mathrm{C}$ and washed twice in Brackett and Oliphant (BO) medium [18]. Centrifugation was performed at $1,680 \times \mathrm{g}$ for $5 \mathrm{~min}$ in 10 $\mathrm{mL}$ BO medium. The final sperm pellet was allowed to settle at $37^{\circ} \mathrm{C}$ for $90 \mathrm{~s}$ without shaking, and the supernatant was collected using the swim-up method. Motility was assessed by placing a drop of semen $(5 \mathrm{~mL})$ on a prewarmed slide and assessing 100 sperms under a phase contrast microscope (40). A minimum of three straws from each of the three ejaculates from each bull ( $\mathrm{n}=9$ straws per bull) were analyzed for a range of in vitro sperm functional assessments $[9,14]$. BO's fertilization medium [18] was placed as $50 \mu \mathrm{L}$ drops covered with warm mineral oil in a $35-\mathrm{mm}$ culture dish and incubated at $38.5^{\circ} \mathrm{C}$ in $5 \% \mathrm{CO}_{2}$. The COCs that matured in vitro were washed thrice and placed in $50 \mu \mathrm{L}$ drops of pre-equilibrated IVF medium covered with warm mineral oil in a $35-\mathrm{mm}$ culture dish (30 COCs per drop). Fifty tiny drops of supernatant solution containing sperm (minimum concentration of $1.0 \times 10^{7}$ spermatozoa $/ \mathrm{mL}$ ) were then added to the drops that contained COCs and were incubated at $38.5^{\circ} \mathrm{C}$ under conditions of $5 \% \mathrm{CO}_{2}$ and high humidity for fertilization [17-19].

At $6 \mathrm{~h}$ after coculturing, COCs were washed and transferred (30 to 50 COCs per well) to a Nunc 4 -well dish containing $500 \mu \mathrm{L}$ embryo culture medium [9] covered with $500 \mu \mathrm{L}$ mineral oil and cultured in modular incubation chambers (615300; ICN Biomedical, Inc., Aurora, OH, USA) at $38.5^{\circ} \mathrm{C}$ in air containing $5 \% \mathrm{CO}_{2}$ and $100 \%$ humidity for $48 \mathrm{~h}$ to assess fertilization as indicated by embryo cleavage. Cleaved 2 -cell embryos were continuously cultured for 7 days to observe blastocyst formation [20]. The sex of the blastocysts was analyzed by polymerase chain reaction [21]. For each bull, three different batches of frozen semen were used for the IVF experiments.

\section{Artificial insemination}

Heifers aged 13 to 15 months, weighing approximately 350 $\mathrm{kg}$, and cows with 2 to 3 parity with a regular estrus period of 60 to 90 days after delivery were selected for AI following healthy examination, and also we avoid normally hot summer of July to August and cold winter of December to January, to eliminate the differences due to the climate influence. Then, AI with conventional frozen or sexed frozen semen was per- formed in three 5,000 large-scale Holstein farms. A pedometer computer information monitoring system was used to confirm the estrus and ovulation periods of the cow. The ovulatory side was determined by rectal examination, and the uterine horn was injected with semen $\left(2 \times 10^{7}\right.$ sperm $) 10$ to $12 \mathrm{~h}$ after the estrus period (4 to $6 \mathrm{~h}$ before or after ovulation). After 35 days of AI, B ultrasonic detection was used to confirm the conception of the cows. AI treatment for all recipients of 1 to 3 parities were performed by same AI and veterinary working group.

\section{Statistical analysis}

The AI conception and IVF rates of conventional frozen and sexed frozen semen from different bulls were analyzed using the SPSS17.0 software [22]. Nine bulls were classified according to the results of the experiment. Data are presented as per the results of $\mathrm{X}^{2}$ analysis.

\section{RESULTS}

\section{Assessment of sperm quality}

Semen quality indices, including sperm density, motility, and deformity rates, of nine bulls used in the experiment are presented in Table 1 . The sperm density of each bull was $>700$ million $/ \mathrm{mL}$; average sperm motility was $>60 \%$, and the average sperm deformity rate was $<18 \%$. The quality of sperm conforms to the national standard for the production of frozen semen.

\section{Correlation between the in vitro fertilization and artificial insemination conception rates for conventional frozen semen}

A total of 491 mature oocytes were used for IVF, and 8,800 cows were used for AI, with conventional frozen semen from nine bulls. The rates of fertilization and blastocyst development, and embryonic sex of IVF as well as the rates of conception and calf sex of AI are summarized in Table 2.

Table 1. Sperm quality of nine bulls

\begin{tabular}{lccccc}
\hline $\begin{array}{l}\text { Sequence } \\
\text { number }\end{array}$ & Bull number & CPI & $\begin{array}{c}\text { Sperm } \\
\text { density } \\
(\mathbf{1 0} / \mathbf{m L})\end{array}$ & $\begin{array}{c}\text { Sperm } \\
\text { motility \% }\end{array}$ & $\begin{array}{c}\text { Sperm } \\
\text { deformity } \\
\text { rate \% }\end{array}$ \\
\hline 1 & 15510187 & 202 & 15.8 & 65 & 13.3 \\
2 & 15505930 & 1,505 & 7.6 & 61 & 14.0 \\
3 & 15504217 & 893 & 17.3 & 69 & 13.1 \\
4 & 15510145 & 288 & 10.5 & 67 & 14.2 \\
5 & 15503330 & 405 & 14.0 & 66 & 15.0 \\
6 & 15510205 & 135 & 13.2 & 63 & 13.7 \\
7 & 15504884 & 172 & 18.1 & 63 & 14.5 \\
8 & 15503863 & -986 & 12.0 & 67 & 12.1 \\
9 & 15503763 & -332 & 13.7 & 65 & 14.4 \\
\hline
\end{tabular}

$\mathrm{CPI}$, China performance index. 
Table 2. Comparison of the in vitro fertilization and artificial insemination conception rates of conventional frozen semen from nine bulls

\begin{tabular}{|c|c|c|c|c|c|}
\hline \multirow{2}{*}{ Bull number } & \multicolumn{3}{|c|}{ IVF rates $^{1)}$} & \multicolumn{2}{|c|}{ Al rates ${ }^{1)}$} \\
\hline & 2-Cell \% & Blast. \% & Embryos $+/$ Total $\%{ }^{2)}$ & Conception \% & Calves $+/$ Total \% ${ }^{2)}$ \\
\hline 15510187 & $48.4(31 / 64)$ & $35.5(11 / 31)$ & $45.5(5 / 11)$ & $43.3(265 / 612)$ & $49.1(130 / 265)$ \\
\hline 15504217 & $64.9(37 / 57)$ & $32.4(12 / 37)$ & $58.3(7 / 12)$ & $56.0(1,100 / 1,963)$ & $48.4(52 / 110)$ \\
\hline 15510145 & $71.7(43 / 60)$ & $37.2(16 / 43)$ & $50.0(8 / 16)$ & $48.5(204 / 421)$ & $51.0(53 / 104)$ \\
\hline 15503330 & $74.0(37 / 50)$ & $35.1(13 / 37)$ & $46.2(6 / 13)$ & $54.9(388 / 707)$ & $47.9(186 / 388)$ \\
\hline 15503863 & $91.7(44 / 48)$ & $36.4(16 / 44)$ & $56.3(9 / 16)$ & $58.4(976 / 1,671)$ & $51.0(498 / 976)$ \\
\hline 15503763 & $95.8(46 / 48)$ & $37.0(17 / 46)$ & $53.0(9 / 17)$ & $56.2(203 / 361)$ & $50.2(102 / 203)$ \\
\hline
\end{tabular}

IVF, in vitro fertilization; Al, artificial insemination.

1) The rates of 2-cell and blastocyst embryos were calculated at $48 \mathrm{~h}$ and 7 days after IVF, respectively.

2) The rates of $q$ embryos/total of IVF blastocyst embryos were analyzed following polymerase chain reaction, and each bull was tested but not for $>50$ embryos.

Three different batches of conventional frozen semen of each bull were used for IVF experiments, and the corresponding AI results were obtained. The rates of fertilization, blastocyst development, and female embryos in the IVF experiments ranged from $48.4 \%$ to $95.8 \%, 29.5 \%$ to $37.2 \%$, and $44.4 \%$ to $58.8 \%$ and the rates of AI conception and female calves ranged from $38.5 \%$ to $61.9 \%$ and $47.8 \%$ to $51.0 \%$ from the nine bulls, respectively. The IVF rates of three bulls $(15504884,15503863$, and 15503763$)$ were $>81.4 \%$, whereas counterpart AI conception rates ranged from $56.2 \%$ to $61.9 \%$. For four bulls $(15504217,15510145,15503330$, and 15510205 ), IVF rates ranged from $64.0 \%$ to $80.0 \%$ and the counterpart AI conception rates ranged from $48.1 \%$ to $56.0 \%$. For two bulls (15510187 and 15505930 ), IVF rates ranged from $48.4 \%$ to $56.0 \%$ and the counterpart AI conception rates ranged from $38.5 \%$ to $43.3 \%$. A correlation analysis showed that there was a positive correlation between the AI conception and IVF rates $(r=0.73, p<0.05$, Figure $2 a)$.

\section{Correlation between the in vitro fertilization and artificial insemination conception rates of sexed frozen semen}

A total of 686 mature oocytes were used for IVF and 7,750 cows were used for AI, with sexed frozen semen from the same nine bulls. The rates of fertilization, blastocyst development, and female embryos of IVF and the rates of conception and female calves of AI are summarized in Table 3. Three different batches of sexed frozen semen of each bull were used for the IVF experiments, and the corresponding AI results were obtained. The rates of fertilization, blastocyst development, and female embryos ranged from $48.9 \%$ to $88.6 \%, 27.1 \%$ to $39.0 \%$, and $75.0 \%$ to $100.0 \%$, and the rates of AI conception and female calves ranged from $40.3 \%$ to $65.2 \%$ and $90.0 \%$ to $95.0 \%$ from the nine bulls, respectively. IVF rates of three bulls $(15504884,15503863$, and 15503763) was $>81.7 \%$, and counterpart AI conception rates ranged from $62.4 \%$ to $65.2 \%$. For four bulls (15504217, 15510145 , 15503330 , and 15510205$)$, IVF rates ranged from $64.0 \%$ to
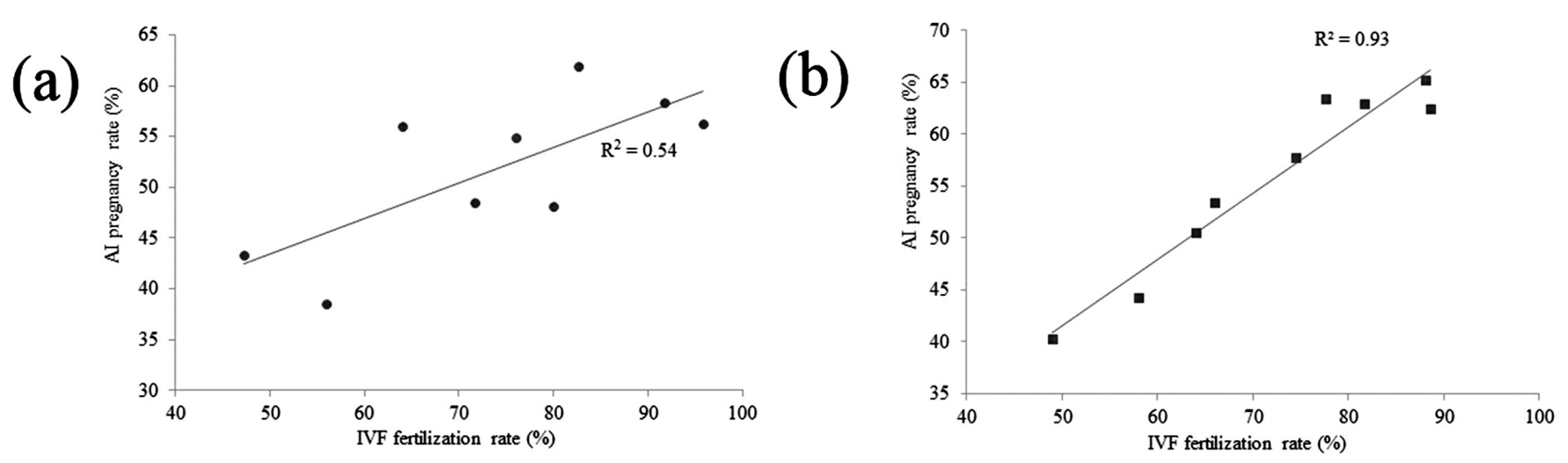

Figure 2. Correlation between the AI pregnancy rate and IVF fertilization rate by using conventional frozen semen (a) and sexed frozen semen (b). Correlation cofficients between Al pregnancy rate and IVF fertilization rate by using (a) conventional frozen semen $(r=0.73, p<0.05)$ and $(b)$ sexed frozen semen $(r=0.97, p<0.01)$ were shown. Two lines show the trends in the data. IVF, in vitro fertilization; Al, artificial insemination. 
Table 3. Comparison of the in vitro fertilization and artificial insemination conception rates of sexed frozen semen from nine bulls

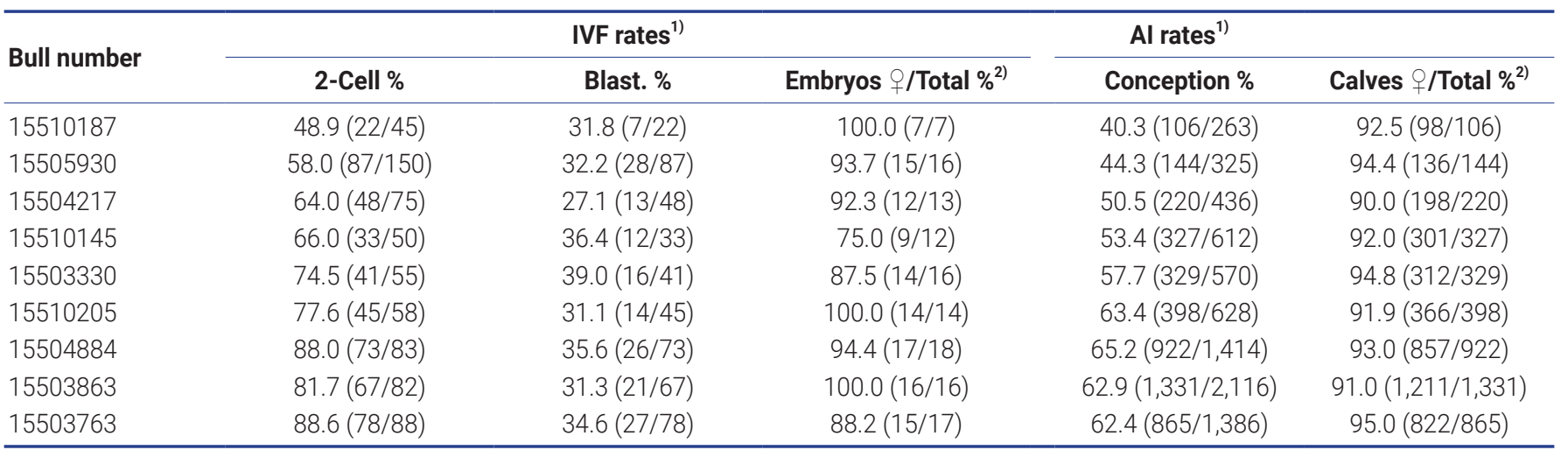

IVF, in vitro fertilization; Al, artificial insemination.

1) The rates of 2-cell and blastocyst embryos were calculated at $48 \mathrm{~h}$ and 7 days after IVF, respectively.

2) The rates of $q$ / total of IVF blastocyst embryos were analyzed following polymerase chain reaction, and each bull was tested but not for $>50$ embryos.

Table 4. Comparison of the conception rate in different artificial insemination cow parities

\begin{tabular}{lccc}
\hline Item & 1 parity ${ }^{\text {1) }}$ & 2 parity & 3 parity $^{\text {1) }}$ \\
\hline Conventional frozen semen Al \% & $69.5(2,677 / 3,852)$ & $61.8(1,853 / 2,998)$ & $48.2(1,915 / 3,974)$ \\
Sexed frozen semen Al \% & $64.2(2,606 / 4,059)$ & $58.8(2,430 / 4,132)$ & $46.2(2,123 / 4,595)$ \\
\hline
\end{tabular}

$\mathrm{Al}$, artificial insemination.

1) The average IVF rates of bulls 15504884,15503863 , and 15503763 in conventional and sexed frozen semen were $90.0 \%$ and $86.1 \%$, respectively, which were used in the above Al treatment with 1 to 3 parities.

$77.6 \%$ and counterpart AI conception rates ranged from $50.5 \%$ to $63.4 \%$. For two bulls (15510187 and 15505930 ), IVF rates ranged from $48.9 \%$ to $58.0 \%$ and counterpart AI conception rates ranged from $40.3 \%$ to $44.3 \%$. A correlation analysis showed that there was a significant correlation between the AI conception and IVF rates $(r=0.97, p<0.01$, Figure $2 b)$.

\section{Effects of artificial insemination cow parities on} artificial insemination conception rate

Three bulls (15504884, 15503863, and 15503763) with high IVF rates were selected to produce conventional frozen and sexed frozen semen on a large scale. AI conception rates of 23,610 cows with different cow parities were compared (Table 4). The average conception rate of AI was $69.5 \%$ in first-born cows, $61.8 \%$ in second-born cows, and $48.2 \%$ in third-born cows when conventional frozen semen was used, whereas it was $64.2 \%, 58.8 \%$, and $46.2 \%$, respectively, when sexed frozen semen was used. Compared with the average fertilization rate of IVF, the AI conception rate of both conventional frozen and sexed frozen semen decreased as the AI cow parity increased; however, a correlation with the fertilization rate was noted $(\mathrm{p}<0.05)$.

The software SPSS17.0 was used to analyze the variance and to test the significant difference and correlation between the IVF and AI conception rates of the bulls (Table 5). Consequently, the AI conception rate showed a significant correlation with the IVF rate $(\mathrm{p}<0.05)$.

\section{DISCUSSION}

In vitro fertilization was positively correlated with artificial insemination conception rates

Some studies suggest that the outcome of IVF is useful for predicting the AI conception rate of bull semen and the ability to support early embryo development [14,23]; however, there are some controversies that need to be investigated further $[9,24]$, and also take an evaluate standard from IVF to AI conception rate (Table 6).

In this study, the correlation between the AI conception and IVF rates were investigated by using conventional and sexed frozen semen from nine bulls. The average rates of IVF and AI conception were approximately $48.4 \%$ to $95.8 \%$ and $43.3 \%$ to $58.4 \%$, respectively, when using conventional frozen semen. The average rates of IVF and AI conception were approximately $48.9 \%$ to $88.6 \%$ and $40.3 \%$ to $65.2 \%$ re-

Table 5. Correlation between the artificial insemination conception and in vitro fertilization rates using conventional and sexed frozen semen

\begin{tabular}{lc}
\hline Items & Index \\
\hline Conventional frozen semen & $0.925^{\star}$ \\
Sexed frozen semen & $0.963^{\star \star}$ \\
\hline
\end{tabular}

* Indicates difference $p<0.05 ; * \star$ Indicates difference $p<0.01$. 
Table 6. Grading the standard to evaluate the conception ability of bulls

\begin{tabular}{|c|c|c|c|}
\hline Standard for evaluation of fertility in bulls & IVF rate range $(\%)$ & Al conception rate range $(\%)$ & Bull number \\
\hline Grade 1: normal fertility bulls & 45 to 60 & $40 \pm 5$ & $\begin{array}{l}15505930 \\
15510187\end{array}$ \\
\hline Grade 2: higher fertility bulls & 61 to 80 & $50 \pm 5$ & $\begin{array}{l}15504217 \\
15510145 \\
15503330 \\
15510205\end{array}$ \\
\hline
\end{tabular}

IVF, in vitro fertilization; $\mathrm{Al}$, artificial insemination.

spectively when using sexed frozen semen. Based on these results, we found that the IVF rates, which were compartmentalized with different fertility abilities, were positively correlated with AI conception rates in each of the nine bulls by using either conventional frozen semen $(r=0.73, p<0.05)$ or sexed frozen semen $(r=0.97, p<0.01)$, including AI recipient changes with different AI recipient parities.

New evaluation standard for the fertilization ability of bulls based on in vitro fertilization test results

Considering the rates of IVF and embryonic development and the sex ratio, we conclude that the IVF rate in both conventional and sexed frozen semen can be used as a criterion for evaluating the bull AI conception ability. Thus, we propose an evaluation standard for the fertilization ability of bulls as per their IVF test results. This evaluation standard of the bull AI conception ability is categorized into three grades (Table 6): grade one, normal fertility bulls with an AI conception rate of $40 \% \pm 5 \%$ and IVF rate of $45 \%$ to $60 \%$; grade two, higher fertility bulls with an AI conception rate of $50 \%$ $\pm 5 \%$ and IVF rate of $61 \%$ to $80 \%$; and grade three, highest fertility bulls with an AI conception rate of $6 \% \pm 5 \%$ and IVF rate of $>80 \%$.

\section{CONCLUSION}

The IVF can be used as a bull breeding index to evaluate bull AI conception, which was classified into three grades, namely, normal fertility, higher fertility, and highest fertility. It provides a more useful index than the genome-wide detection of Holstein bull breeding ability.

\section{CONFLICT OF INTEREST}

We certify that there is no conflict of interest with any financial organization regarding the material discussed in the manuscript.

\section{ACKNOWLEDGMENTS}

This study was financially supported by the Project of Development and application of new technology for aerospace biological breeding of Holstein cattle, beef cattle and mutton sheep-development and application of the new technology of sex-controlled propagation (NO.ZDZX2016019), which founding from Inner Mongolia Government. The authors thank Inner Mongolia Saikexing Reproductive Biotechnology (Group) Co., Ltd.

\section{REFERENCES}

1. Kocks JEM, Broekhuijse MLWJ. The practical use of density of whole bull semen to determine the volume of an ejaculate at AI laboratories. Anim Reprod Sci 2014;146:98-102. https:// doi.org/10.1016/j.anireprosci.2014.02.015

2. Attia S, Katila T, Andersson M. The effect of sperm morphology and sire fertility on calving rate of Finnish ayrshire AI bulls. Reprod Domest Anim 2016;51:54-8. https://doi. org/10.1111/rda.12645

3. Lecewicz M, Kordan W, Majewska A, Kamiński S, Dziekońska A, Mietelska K. Effects of the platelet-activating factor (PAF) on selected quality parameters of cryopreserved bull semen (AI) with reduced sperm motility. Pol J Vet Sci 2016;19:14758. https://doi.org/10.1515/pjvs-2016-0019

4. Paakala E, Martín-Collado D, Mäki-Tanila A, Juga J. Variation in the actual preferences for AI bull traits among Finnish dairy herds. J Anim Breed Genet 2018;135:410-9. https:// doi.org/10.1111/jbg.12359

5. Maicas C, Hutchinson IA, Kenneally J, et al. Fertility of fresh and frozen sex-sorted semen in dairy cows and heifers in seasonal-calving pasture-based herds. J Dairy Sci 2019;102: 10530-42. https://doi.org/10.3168/jds.2019-16740

6. Zhang J, Guo HM, Su J, et al. A comparison of the effects of pentoxifylline on quality of fresh and frozen-thawed bull spermatozoa. Agric Biotechnol 2014;3:20-4. https://doi.org/ 10.19759/j.cnki.2164-4993.2014.03.007

7. Lopes G, Ferreira P, Rocha A. Bull frozen semen accidentally 
exposed to room temperature for $5 \mathrm{~s}$ presents reduced blastocyst formation after IVF. Anim Reprod Sci 2016;169:133. https://doi.org/10.1016/j.anireprosci.2016.03.087

8. Kipper BH, Trevizan JT, Carreira JT, et al. Sperm morphometry and chromatin condensation in Nelore bulls of different ages and their effects on IVF. Theriogenology 2017;87:15460. https://doi.org/10.1016/j.theriogenology.2016.08.017

9. Holden SA, Fernandez-Fuertes B, Murphy C, et al. Relationship between in vitro sperm functional assessments, seminal plasma composition, and field fertility after AI with either non-sorted or sex-sorted bull semen. Theriogenology 2017; 87:221-8. https://doi.org/10.1016/j.theriogenology.2016.08. 024

10. Seidel GE. Sexing mammalian sperm-intertwining of commerce, technology, and biology. Anim Reprod Sci 2003;79: 145-56. https://doi.org/10.1016/S0378-4320(03)00162-3

11. Moore SG, Hasler JF. A 100-Year Review: Reproductive technologies in dairy science. J Dairy Sci 2017;100:10314-31. https://doi.org/10.3168/jds.2017-13138

12. Bousquet $\mathrm{D}$, Twagiramungu $\mathrm{H}$, Morin $\mathrm{N}$, Brisson C, Carboneau $\mathrm{G}$, Durocher J. In vitro embryo production in the cow: an effective alternative to the conventional embryo production approach. Theriogenology 1999;51:59-70. https:// doi.org/10.1016/S0093-691X(98)00231-3

13.Xu J, Guo Z, Su L, et al. Developmental potential of vitrified holstein cattle embryos fertilized in vitro with sex-sorted sperm. J Dairy Sci 2006;89:2510-8. https://doi.org/10.3168/ jds.S0022-0302(06)72326-8

14. Marquant-Le Guienne B, Humblot P, Thibier M, Thibault C. Evaluation of bull semen fertility by homologous in vitro fertilization tests. Reprod Nutr Dev 1990;30:259-66. https:// doi.org/10.1051/rnd:19900212

15. Hunter RHF, Li XH. Egg-embryo transfer: an analytical tool for vintage experiments in domestic farm animals. J Agric Sci Technol-Iran 2013;15:65-70. https://doi.org/10.3969/j. issn.1008-0864.2013.01.11

16.Eckert J, Niemann H. In vitro maturation, fertilization and culture to blastocysts of bovine oocytes in protein-free media.
Theriogenology 1995;43:1211-25. https://doi.org/10.1016/ 0093-691X(95)00093-N

17.Li XH, Iwasaki S, Nakahara T. Effects of trophectoderm dissection on development of inner cell mass of fresh and frozenthawed bovine blastocysts derived from in-vitro fertilization. J Reprod Dev 1993;39:281-6. https://doi.org/10.1262/jrd.39. 281

18. Brackett BG, Bousquet D, Boice ML, Donawick WJ, Evans JF, Dressel MA. Normal development following in vitro fertilization in the cow. Biol Reprod 1982;27:147-58. https:// doi.org/10.1095/biolreprod27.1.147

19. Kim IH, Soom AV, Langendonckt AV, Bevers MM. The effect of glutathione added to IVF medium on embryo development is bull dependent. Theriogenology 1999;51:321. https:// doi.org/10.1016/S0093-691X(99)91880-0

20.McEvoy TG, Sreenan JM. Effect of embryo quality and stage of development on the survival of zona pellucida-free cattle demi-embryos. Theriogenology 1990;33:1245-53. https:// doi.org/10.1016/0093-691X(90)90042-R

21. Herr CM, Reed KC. Micronanipulation of bovine embryos for sex determination. Theriogenology 1991;35:45-54. https:// doi.org/10.1016/0093-691X(91)90147-6

22.Zhang J, Su J, Hu SX, et al. Correlation between ubiquitination and defects of bull spermatozoa and removal of defective spermatozoa using anti-ubiquitin antibody-coated magnetized beads. Anim Reprod Sci 2018;192:44-52. https://doi.org/10. 1016/j.anireprosci.2018.01.018

23.Zhang BR, Larsson B, Lundeheim N, Rodriguez-Martinez H. Relationship between embryo development in vitro and 56day nonreturn rates of cows inseminated with frozenthawed semen from dairy bulls. Theriogenology 1997;48: 221-31. https://doi.org/10.1016/S0093-691X(97)84069-1

24.Dhali A, Anchamparuthy VM, Butler SP, Pearson RE, Gwazdauskas FC. In vitro development of bovine embryos cultured with stem cell factor or insulin-like growth factor-I following IVF with semen of two bulls having different field fertility. Anim Reprod Sci 2009;116:188-95. https://doi.org/10.1016/j. anireprosci.2009.02.007 